\title{
Tanzawaic acids I-L: Four new polyketides from Penicillium sp. IBWF104-06
}

\author{
Louis P. Sandjo ${ }^{1}$, Eckhard Thines ${ }^{2,3}$, Till Opatz ${ }^{* 1}$ and Anja Schüffler ${ }^{* 2}$
}

\section{Full Research Paper}

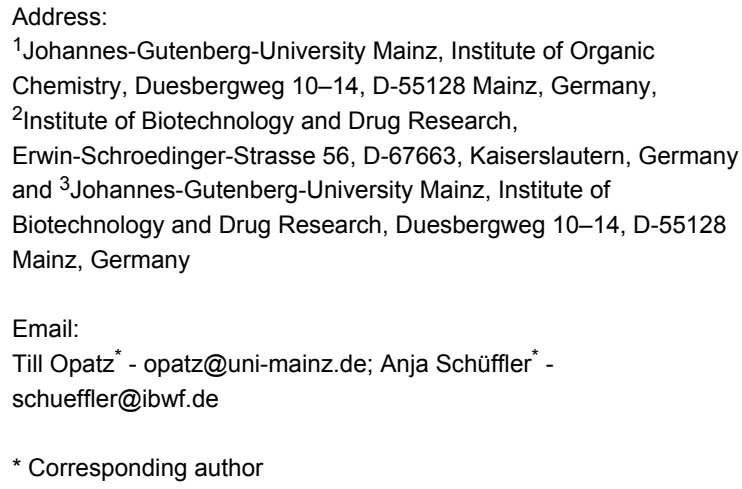

1Johannes-Gutenberg-University Mainz, Institute of Organic Chemistry, Duesbergweg 10-14, D-55128 Mainz, Germany, ${ }^{2}$ Institute of Biotechnology and Drug Research, Erwin-Schroedinger-Strasse 56, D-67663, Kaiserslautern, Germany and ${ }^{3}$ Johannes-Gutenberg-University Mainz, Institute of Biotechnology and Drug Research, Duesbergweg 10-14, D-55128 Mainz, Germany

Email:

Till Opatz - opatz@uni-mainz.de; Anja Schüffler ${ }^{*}$ schueffler@ibwf.de

* Corresponding author

Keywords:

arohynapene; natural products; polyketides; structure elucidation; tanzawaic acid
Beilstein J. Org. Chem. 2014, 10, 251-258.

doi:10.3762/bjoc. 10.20

Received: 26 September 2013

Accepted: 20 December 2013

Published: 22 January 2014

This article is part of the Thematic Series "Natural products in synthesis and biosynthesis".

Guest Editor: J. S. Dickschat

(C) 2014 Sandjo et al; licensee Beilstein-Institut.

License and terms: see end of document.

\begin{abstract}
Four new polyketides have been identified in culture filtrates of the fungal strain Penicillium sp. IBWF104-06 isolated from a soil sample. They are structurally based on the same trans-decalinpentanoic acid skeleton as tanzawaic acids A-H. One of the new compounds was found to inhibit the conidial germination in the rice blast fungus Magnaporthe oryzae at concentrations of $25 \mu \mathrm{g} / \mathrm{mL}$.
\end{abstract}

\section{Introduction}

Nature still represents the richest source of new antimicrobials which can be attractive as lead structures or biochemical tools for target identification for medical applications as well as for crop science. In both areas, the omnipresent development of resistance results in a demand for new active principles for which the structural diversity of nature holds an excellent supply. While natural products, their synthesis, evolution, and ecological role are of academic interest, compounds identified might also be relevant for application. In the course of investigations into the secondary metabolism of fungal species for the identification of novel lead structures for agrochemical and pharmaceutical research, we isolated a fungal strain from a soil sample. The culture filtrate extract of this organism was found to inhibit the conidial germination in the rice blast fungus Magnaporthe oryzae, one of the most devastating plant diseases on cultivated rice. Bioactivity-guided fractionation of organic extracts led to the isolation of a series of eight pure compounds, the structures of which were elucidated by 2D NMR spectroscopy as well as by mass spectrometry.

\section{Results and Discussion}

Structure elucidation. Compound $\mathbf{1}$ has the molecular formula $\mathrm{C}_{18} \mathrm{H}_{26} \mathrm{O}_{4}$ determined on the basis of NMR and HRMS-ESI data which gave a pseudo-molecular ion at $\mathrm{m} / \mathrm{z} 329.1744$ (calcd 
for $[\mathrm{M}+\mathrm{Na}]^{+}:$329.1729). This composition accounted for six double bond equivalents. The NMR spectra of 1 (Table 1 and Table 2) displayed signals of a $(2 E, 4 E)$-penta-2,4-dienoic acid moiety including a carbon of a conjugated carbonyl group at $\delta_{\mathrm{C}}$
170.9 and four olefinic resonances at $\delta_{\mathrm{H}} 5.86(\mathrm{~d}, J=15.3 \mathrm{~Hz}) /$ $\delta_{\mathrm{C}} 122.0, \delta_{\mathrm{H}} 7.28(\mathrm{dd}, J=11.2,15.3 \mathrm{~Hz}) / \delta_{\mathrm{C}} 145.9, \delta_{\mathrm{H}} 6.45(\mathrm{dd}$, $J=11.2,15.2 \mathrm{~Hz}) / 128.5$, and $\delta_{\mathrm{H}} 6.10(\mathrm{~d}, J=15.2 \mathrm{~Hz}) / \delta_{\mathrm{C}} 144.8$. Moreover, these spectra showed signals of three $\mathrm{CH}_{3}$ groups,

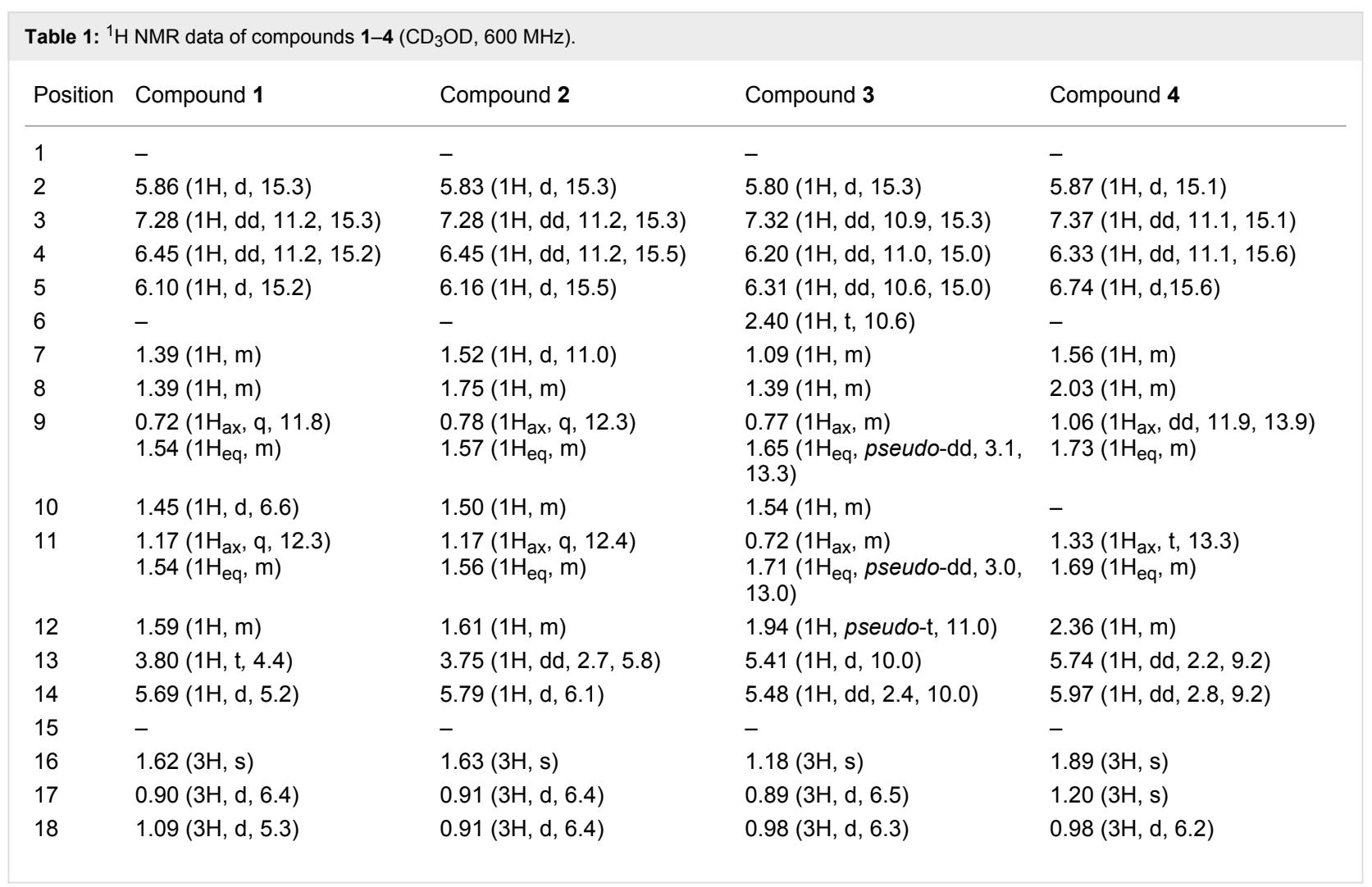

\begin{tabular}{|c|c|c|c|c|}
\hline Position & Compound 1 & Compound 2 & Compound 3 & Compound 4 \\
\hline 1 & 170.9 & 170.9 & 170.9 & 170.9 \\
\hline 2 & 122.0 & 121.3 & 120.6 & 120.8 \\
\hline 3 & 145.9 & 146.2 & 146.7 & 147.1 \\
\hline 4 & 128.5 & 127.8 & 130.5 & 131.0 \\
\hline 5 & 144.8 & 153.7 & 147.5 & 142.3 \\
\hline 6 & 79.0 & 76.1 & 58.8 & 133.4 \\
\hline 7 & 49.8 & 49.1 & 51.1 & 49.9 \\
\hline 8 & 35.3 & 34.3 & 37.2 & 29.1 \\
\hline 9 & 47.1 & 47.1 & 48.1 & 49.3 \\
\hline 10 & 32.9 & 33.0 & 33.7 & 70.1 \\
\hline 11 & 39.1 & 39.0 & 42.8 & 44.0 \\
\hline 12 & 41.4 & 39.9 & 44.7 & 35.9 \\
\hline 13 & 67.6 & 68.0 & 132.9 & 137.3 \\
\hline 14 & 127.0 & 128.0 & 135.2 & 131.0 \\
\hline 15 & 142.9 & 140.9 & 74.5 & 133.8 \\
\hline 16 & 18.1 & 19.1 & 24.6 & 19.8 \\
\hline 17 & 23.1 & 23.1 & 22.8 & 31.3 \\
\hline 18 & 23.0 & 24.2 & 23.8 & 23.4 \\
\hline
\end{tabular}


two $\mathrm{CH}_{2}$ groups, six $\mathrm{CH}$ groups, and two quaternary carbons (Table 1 and Table 2). These data suggested a structural similarity of $\mathbf{1}$ to the tanzawaic acids, secondary metabolites from Penicillium citrinum [1]. COSY and HMBC correlations (Figure 1) revealed the presence of a trans-decalin scaffold containing six $\mathrm{CH}$ groups, two $\mathrm{CH}_{2}$ groups and two quaternary carbons as the hydrogen at $\delta_{\mathrm{H}} 1.39(\mathrm{H}-7)$ showed correlations with hydrogens at $\delta_{\mathrm{H}} 1.59(\mathrm{H}-12)$ and $0.72(\mathrm{H}-9)$ while the latter correlated with the proton at $\delta_{\mathrm{H}} 1.45(\mathrm{H}-10)$. Likewise, the resonance at $\delta_{\mathrm{H}} 1.45$ had a correlation with the proton at $\delta_{\mathrm{H}}$ $1.17\left(\mathrm{H}-11_{\mathrm{ax}}\right)$ which in turn correlated with those at $\delta_{\mathrm{H}} 1.54$ $\left(\mathrm{H}-11_{\mathrm{eq}}\right)$ and $1.59(\mathrm{H}-12)$ forming the western part of the bicyclic framework; further homonuclear interactions were revealed from $\mathrm{H}-12\left(\delta_{\mathrm{H}} 1.59\right)$ to $\mathrm{H}-13\left(\delta_{\mathrm{H}} 3.80\right)$ and $\mathrm{H}-14\left(\delta_{\mathrm{H}}\right.$ 5.69). The eastern part of the decalin system was established based on $\mathrm{HMBC}$ correlations between the olefinic proton at $\delta_{\mathrm{H}}$ $5.69(\mathrm{H}-14)$ and the carbons $\mathrm{C}-12\left(\delta_{\mathrm{C}} 41.4\right), \mathrm{C}-13\left(\delta_{\mathrm{C}} 67.6\right)$, and $\mathrm{C}-6\left(\delta_{\mathrm{C}} 79.0\right)$ while the hydrogen of the oxymethine at $\delta_{\mathrm{H}}$ 3.80 (H-13) correlated with the carbons C-7 $\left(\delta_{\mathrm{C}} 49.8\right), \mathrm{C}-14\left(\delta_{\mathrm{C}}\right.$ $127.0)$ and $\mathrm{C}-15\left(\delta_{\mathrm{C}} 142.9\right)$. Based on the COSY and HMBC interactions as well as their 1D multiplicity, the $\mathrm{CH}_{3}$ groups at $\delta_{\mathrm{H}} 0.90(\mathrm{H}-17), 1.09(\mathrm{H}-18)$ and $1.62(\mathrm{H}-16)$ were attached to the carbons resonating at $\delta_{\mathrm{C}} 32.9(\mathrm{C}-10), 35.3(\mathrm{C}-8)$, and 142.9 (C-15) respectively, while the penta-2,4-dienoic acid unit was connected to the carbon at $\delta_{\mathrm{C}} 79.0(\mathrm{C}-6)$.
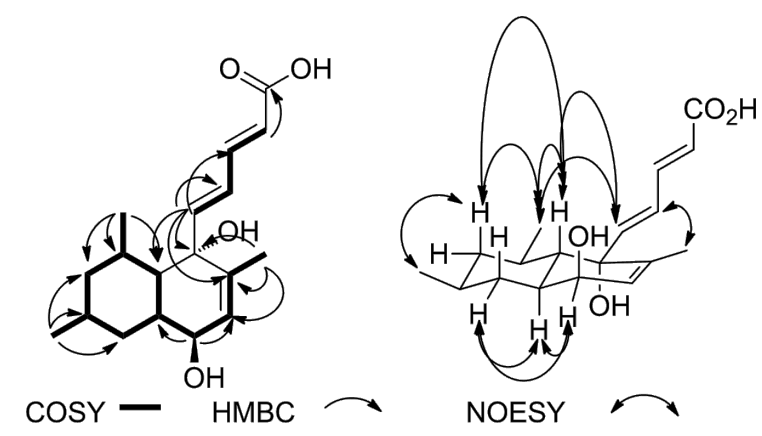

Figure 1: HMBC, COSY and NOESY correlations of compound 1.

The relative configuration of the stereogenic centers was assigned based on NOESY data (Figure 1) and the previous work reported by Malmstrøm et al. on the stereochemistry of two related compounds, tanzawaic acids E and F [2].

The NOESY spectrum showed contacts (Figure 1) between the proton of the oxymethine group at $\delta_{\mathrm{H}} 3.80(\mathrm{H}-13)$ and the protons at $\delta_{\mathrm{H}} 1.54\left(\mathrm{H}-11_{\mathrm{eq}}\right)$ and $1.59(\mathrm{H}-12)$ suggesting an axial orientation of the $\mathrm{OH}$ group at $\mathrm{C}-13$. The proton at $\delta_{\mathrm{H}} 1.17$ $\left(\mathrm{H}-11_{\mathrm{ax}}\right)$ correlated with those at $\delta_{\mathrm{H}} 0.90(\mathrm{H}-17), 0.72(\mathrm{H}-9 \mathrm{ax})$, and $1.39(\mathrm{H}-8)$ while $\mathrm{H}-9_{\mathrm{ax}}$ showed same interactions with the methyl protons at $\delta_{\mathrm{H}} 1.09(\mathrm{H}-18)$ and $0.90(\mathrm{H}-17)$ suggesting them to be oriented equatorially. The same orientation was suggested for the unsaturated side chain since correlations were found between the proton at $\delta_{\mathrm{H}} 6.10(\mathrm{H}-5)$ and those at 1.09 (H-18) and 1.39 (H-7).

The foregoing data in conjunction with those of the structurally related tanzawaic acid E [2] led to the identification of $\mathbf{1}$ as a new member of this compound class and it was given the name tanzawaic acid I (Figure 5).

Compound 2 has the molecular formula $\mathrm{C}_{18} \mathrm{H}_{26} \mathrm{O}_{4}$ deduced from its NMR and HRMS-ESI data which revealed a pseudomolecular ion at $m / z 329.1736$ (calcd for $[\mathrm{M}+\mathrm{Na}]^{+}: 329.1729$ ). As in compound $\mathbf{1}$, this composition accounted for six double bond equivalents. The NMR spectra of compound 2 exhibited features similar to those of $\mathbf{1}$. Signals of a $(2 E, 4 E)$-penta-2,4dienoic acid moiety $\left(\delta_{\mathrm{H}} 5.83(\mathrm{~d}, J=15.3 \mathrm{~Hz}, \mathrm{H}-2) / \delta_{\mathrm{C}} 121.3, \delta_{\mathrm{H}}\right.$ $7.28(\mathrm{dd}, J=11.2,15.3 \mathrm{~Hz}, \mathrm{H}-3) / \delta_{\mathrm{C}} 146.2, \delta_{\mathrm{H}} 6.45(\mathrm{dd}, 11.2$, $15.5 \mathrm{~Hz}, \mathrm{H}-4) / \delta_{\mathrm{C}} 127.8$, and $\delta_{\mathrm{H}} 6.16(\mathrm{~d}, J=15.5 \mathrm{~Hz}, \mathrm{H}-5) / \delta_{\mathrm{C}}$ 153.7 and $\left.\delta_{\mathrm{C}} 170.9(\mathrm{C}-1)\right)$ and a trans-decalin bearing three methyl groups $\left(\delta_{\mathrm{H}} 0.91(\mathrm{~d}, J=6.4 \mathrm{~Hz}, \mathrm{H}-17) / \delta_{\mathrm{C}} 23.1,0.91(\mathrm{~d}\right.$, $J=6.4 \mathrm{~Hz}, \mathrm{H}-18) / \delta_{\mathrm{C}} 24.2$ and $\left.\delta_{\mathrm{H}} 1.63(\mathrm{~s}, \mathrm{H}-16) / \delta_{\mathrm{C}} 19.1\right)$ were found as well as a trisubstituted double bond $\left(\delta_{\mathrm{H}} 5.79(\mathrm{~d}, J=\right.$ $6.1 \mathrm{~Hz}, \mathrm{H}-14) / \delta_{\mathrm{C}} 128.0$ and $\left.\delta_{\mathrm{C}} 140.9(\mathrm{C}-15)\right)$, an oxymethine $\left(\delta_{\mathrm{H}} 3.75(\mathrm{dd}, J=2.7,5.8 \mathrm{~Hz}, \mathrm{H}-13) / \delta_{\mathrm{C}} 68.0\right)$, and a tertiary alcohol $\left(\delta_{\mathrm{C}} 76.1, \mathrm{C}-6\right)$. A careful inspection of COSY and HMBC data (Figure 2) of compound 2 suggested a diastereomeric relationship with $\mathbf{1}$ which was substantiated by the different optical rotations of -262 and +73.7 for compounds 1 and 2 , respectively.

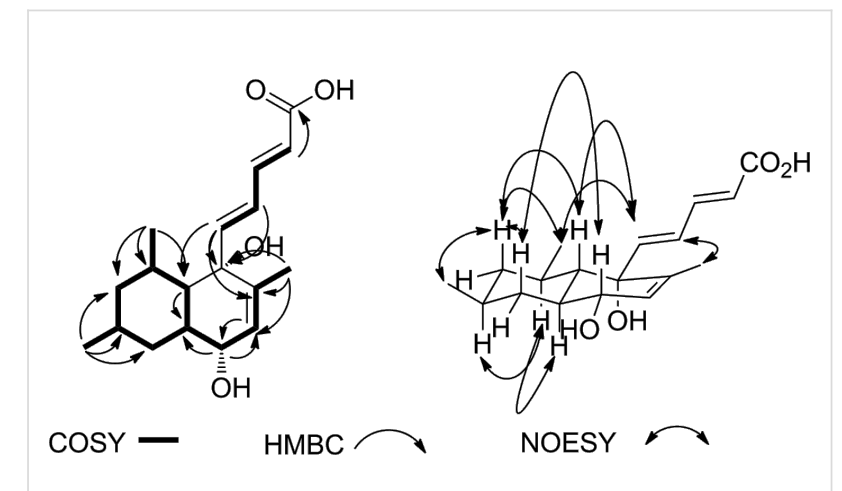

Figure 2: HMBC, COSY and NOESY correlations of compound 2.

In compound 2, NOESY correlations (Figure 2) observed between $\mathrm{H}-11_{\mathrm{ax}}\left(\delta_{\mathrm{H}} 1.17\right)$ and $\mathrm{H}-9_{\mathrm{ax}}\left(\delta_{\mathrm{H}} 0.78\right), \mathrm{H}-13\left(\delta_{\mathrm{H}} 3.75\right)$ and $\mathrm{H}-7\left(\delta_{\mathrm{H}} 1.52\right)$ revealed the oxymethine at $\delta_{\mathrm{H}} 3.75(\mathrm{dd}, J=$ $2.7,6.0 \mathrm{~Hz}) / \delta_{\mathrm{C}} 68.0$ to be responsible for the diastereomery between $\mathbf{1}$ and $\mathbf{2}$ due to inversion of the configuration at C-13. 
Further NOESY correlations were observed between the proton resonating at $\delta_{\mathrm{H}} 0.78\left(\mathrm{H}-9_{\mathrm{ax}}\right)$ and the methyl protons at $\delta_{\mathrm{H}} 0.91$ (Me-17 and Me-18) while $\mathrm{H}-18$ showed the same interactions with the olefinic protons at $\delta_{\mathrm{H}} 6.16(\mathrm{H}-5)$ and $6.45(\mathrm{H}-4)$. This observation suggested 2 to have the same relative configuration as 1 at $\mathrm{C}-6, \mathrm{C}-7, \mathrm{C}-8$, and $\mathrm{C}-10$. The above-mentioned data allowed to identify compound $\mathbf{2}$ as another member of the tanzawaic acid family and was given the name tanzawaic acid $\mathrm{J}$.

The molecular formula of compound $3, \mathrm{C}_{18} \mathrm{H}_{26} \mathrm{O}_{3}$ was established by NMR in conjunction with HRMS-ESI which gave a pseudo-molecular ion at $m / z 313.1788$ (calcd for $[\mathrm{M}+\mathrm{Na}]^{+}$: 313.1780). This composition required six double bond equivalents and differed from those of compounds $\mathbf{1}$ and $\mathbf{2}$ by one oxygen atom. This observation was supported by the absence of oxymethine signals in the NMR spectra. However, features similar to those of the $(2 E, 4 E)$-penta-2,4-dienoic acid moiety of compounds 1 and 2 and some signal patterns of the transdecalin part different from those of the two other compounds were observed. The resonance of $\mathrm{H}-5\left(\delta_{\mathrm{H}} 6.31, J=10.6,15.0\right.$ $\mathrm{Hz}$ ) was found as a doublet of doublets suggesting the side chain to be attached to a methine carbon in the bicyclic portion. This conclusion was confirmed by a COSY-correlation to H-6 $\left[\delta_{\mathrm{H}} 2.40(\mathrm{t}, J=10.6 \mathrm{~Hz})\right]$. Furthermore, two signals of a cis olefin were unveiled at $\delta_{\mathrm{H}} 5.41(\mathrm{~d}, J=10.0 \mathrm{~Hz}) / \delta_{\mathrm{C}} 132.9$ and $\delta_{\mathrm{H}} 5.48(\mathrm{dd}, J=2.4,10.0 \mathrm{~Hz}) / \delta_{\mathrm{C}} 135.2$ and originated from the protons bound to $\mathrm{C}-13$ and $\mathrm{C}-14$. This supposition was consistent with diagnostic $\mathrm{HMBC}$ correlations connecting the protons $\left[\delta_{\mathrm{H}} 1.18(\mathrm{~s})\right]$ of the $\mathrm{C}-16$ methyl group to $\mathrm{C}-6\left(\delta_{\mathrm{C}} 58.8\right), \mathrm{C}-15$ $\left(\delta_{C} 74.5\right)$ as well as $\mathrm{C}-14\left(\delta_{C} 135.2\right)$ (Figure 3$)$.

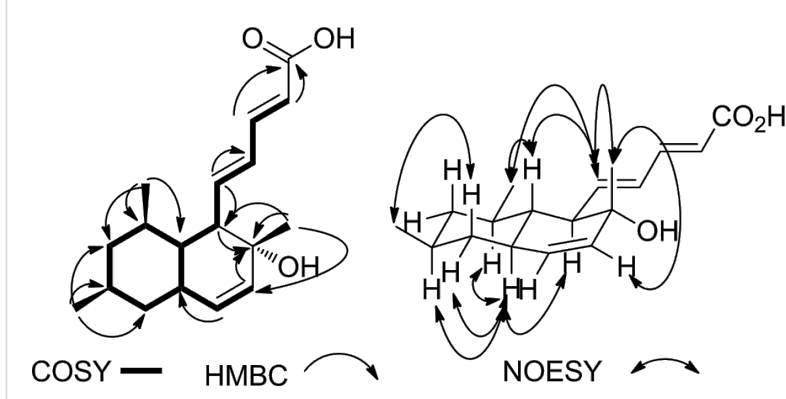

Figure 3: HMBC, COSY and NOESY correlations of compound 3.

The NOESY spectrum of compound 3 revealed similar correlations as in its analogues $\mathbf{1}$ and $\mathbf{2}$ between the olefinic proton $\mathrm{H}-5$ ( $\delta_{\mathrm{H}}$ 6.31) and the $\mathrm{CH}_{3}$ group attached to $\mathrm{C}-8$ suggesting the same relative orientation of the side chain and the $\mathrm{CH}_{3}$ group (Figure 3) which is supported by a correlation between $\mathrm{H}-5$ and the $\mathrm{CH}_{3}(\mathrm{C}-16)$ group $\left(\delta_{\mathrm{H}} 1.18\right)$. The complete assignment led to structure 3 as shown in Figure 5. The compound was named tanzawaic acid $\mathrm{K}$.
The molecular formula of compound $4, \mathrm{C}_{18} \mathrm{H}_{24} \mathrm{O}_{3}$ was determined based on its NMR and HRMS-ESI data which gave a pseudo-molecular ion at $m / z 311.1630$ (calcd for $[\mathrm{M}+\mathrm{Na}]^{+}$: 311.1623). This composition required seven double bond equivalents. It differed from compound $\mathbf{3}$ by two hydrogen atoms suggesting one additional carbon-carbon double bond. This assumption was justified by the presence of four olefinic signals $\left(\delta_{\mathrm{H}} 5.74(\mathrm{dd}, J=2.2,9.2 \mathrm{~Hz}, \mathrm{H}-13) / \delta_{\mathrm{C}} 137.3, \delta_{\mathrm{H}} 5.97\right.$ $(\mathrm{dd}, J=2.8,9.2, \mathrm{H}-14) / \delta_{\mathrm{C}} 131.0, \delta_{\mathrm{C}} 133.4(\mathrm{C}-6)$, and 133.8 (C-15)) in the 1D NMR spectra. The two latter signals were attributed to a tetrasubstituted olefin which was unique for compound 4, along with only one $\mathrm{CH}_{3}$ group appearing as a doublet at $\delta_{\mathrm{H}} 0.98(\mathrm{~d}, J=6.2 \mathrm{~Hz}, \mathrm{H}-18) / \delta_{\mathrm{C}} 23.4$. The second $\mathrm{CH}_{3}$ group observed as a doublet in compounds $\mathbf{1}-\mathbf{3}$ appeared in the ${ }^{1} \mathrm{H}$ NMR spectrum of 4 as a singlet $\left(\delta_{\mathrm{H}} 1.20, \mathrm{H}-17\right)$ and showed a HMBC correlation with the quaternary carbon at $\delta_{\mathrm{C}} 70.1$ (C-10) (Figure 4). As in compounds $\mathbf{1}-\mathbf{3}$, resonances of a $(2 E, 4 E)$-penta-2,4-dienoic acid moiety as well as three additional $\mathrm{CH}$ groups, two $\mathrm{CH}_{2}$ groups and one $\mathrm{CH}_{3}$ for the completion of the decalin part were observed.

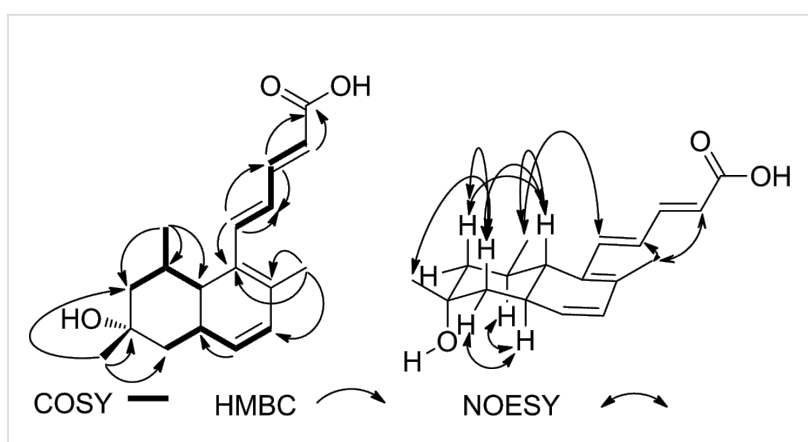

Figure 4: HMBC, COSY and NOESY correlations of compound 4.

The relative configuration of the stereogenic centers was determined by NOESY (Figure 4). Correlations were observed between $\mathrm{H}-7\left(\delta_{\mathrm{H}} 1.56\right)$ and $\mathrm{H}-9_{\mathrm{ax}}\left(\delta_{\mathrm{H}} 1.06\right), \mathrm{H}-11_{\mathrm{ax}}\left(\delta_{\mathrm{H}} 1.33\right)$, and the $\mathrm{C}-18$ methyl protons $\left(\delta_{\mathrm{H}} 0.98\right)$. An additional correlation was found between $\mathrm{H}-11_{\mathrm{ax}}\left(\delta_{\mathrm{H}} 1.33\right)$ and the $\mathrm{C}-17$ methyl protons $\left(\mathrm{H}-17, \delta_{\mathrm{H}} 1.20\right)$ suggesting an equatorial orientation of the latter. From the complete spectral assignment, the structure of compound 4 was established as shown in Figure 5. The fourth member of the series was consequently named tanzawaic acid L (Figure 5).

Along with compounds 1-4, four known polyketides were isolated and identified (Figure 5) as arohynapene A (5) [3], arohynapene B (6) [3], tanzawaic acid A (7) [1], and tanzawaic acid E (8) [2]. Their structures were established based on NMR data and by comparison with those reported in the literature. The structures of arohynapene A and tanzawaic acid E were 


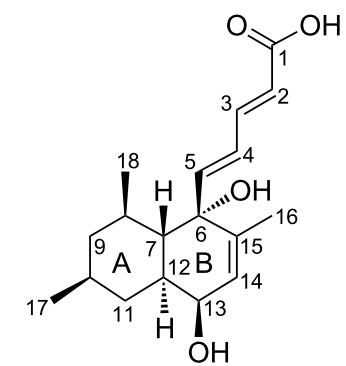

tanzawaic acid I (1)

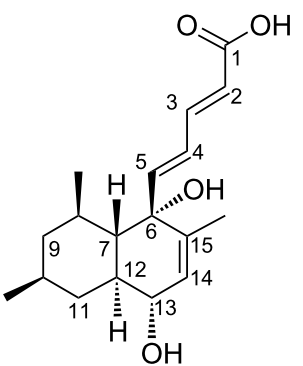

tanzawaic acid J (2)<smiles>CC1CC(C)C2(C)C(C=C[C@](C)(O)C2/C=C/C=C/C(=O)O)C1</smiles>

tanzawaic acid K (3)<smiles>CC1=C(/C=C/C=CC(=O)O)C2(C)C(C)CC(C)(O)CC2C=C1</smiles>

tanzawaic acid L (4)<smiles>Cc1ccc2c(c1/C=C/C=C/C(=O)O)C1C(C)CC(C)C(O)C1C2</smiles>

arohynapene $\mathrm{A}$ (5)<smiles>CC1Cc2ccc(CO)c(/C=C/C=C/C(=O)O)c2C(C)C1</smiles>

arohynapene B (6)<smiles>Cc1ccc2c(c1/C=C/C=C/C(=O)O)C(C)CC(C)C2</smiles>

tanzawaic acid $\mathrm{A}(\mathbf{7})$<smiles>CC1C=C[C@H]2C[C@](C)(O)CC(C)[C@]2(/C=C/C=C/C(=O)O)[C@H]1C</smiles>

tanzawaic acid $E(\mathbf{8})$

Figure 5: Structures of the isolated compounds.

furthermore supported by X-ray crystallography (Figure 6). In the latter case, the absolute configuration could be determined even though no heavy atom is present in the unit cell. The result confirms the synthetic work of Arimoto et al. who determined the configuration of tanzawaic acid A to be $8 R, 10 S$ [4] and suggests the other tanzawaic acids to have the same absolute configuration.
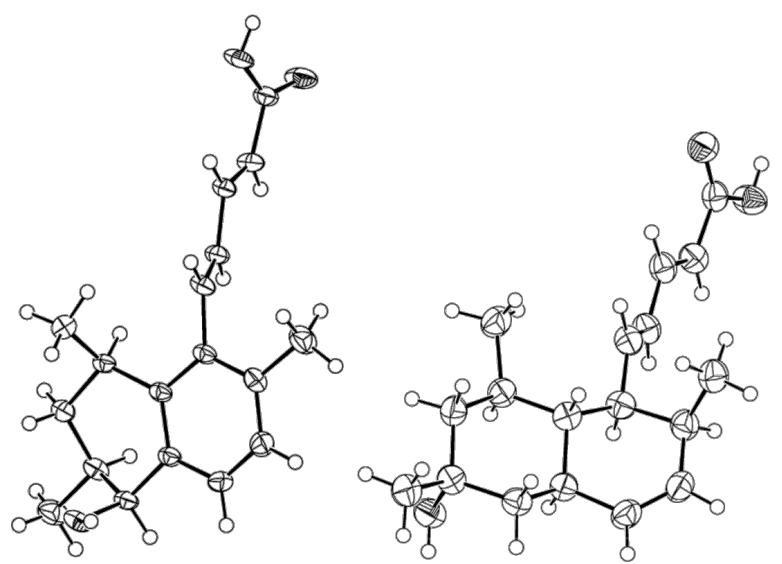

Figure 6: Crystal structures (ORTEP plot) of arohynapene A (5, left) and tanzawaic acid $\mathrm{E}$ (8, right). Thermal ellipsoids are drawn at the $50 \%$ probability level.
Tanzawaic acids were found in different Penicillium species, especially tanzawaic acid A which seems to be omnipresent in Penicillium citrinum [1,2]. Tanzawaic acids E and F were isolated from a marine-derived Penicillium steckii and were detected in at least 16 culture collection strains of the same species in a secondary metabolite study [2].

Recently, El-Neketi et al. [5] described the isolation of two new tanzawaic acids $\mathrm{G}$ and $\mathrm{H}$, as well as tanzawaic acids $\mathrm{B}$ and $\mathrm{F}$ and arohynapene D from an endophytic Penicillium citrinum species. Therefore, Penicillium sp. IBWF104-06 appears to be related by its secondary metabolites to the aforementioned strains which do belong to the Penicillium section Citrina [6]. Tanzawaic acid $\mathrm{E}$ differs from tanzawaic acid $\mathrm{L}$ by two more hydrogen atoms at C-6 and C-15 and has the same elemental composition as tanzawaic acid $\mathrm{K}$, the structural difference being the position of the $\mathrm{OH}$ group located at $\mathrm{C}-15$ of tanzawaic acid $\mathrm{K}$ instead of $\mathrm{C}-10$ in tanzawaic acid $\mathrm{E}$ [2]. Tanzawaic acids I and $\mathrm{J}$ have an $18 \mathrm{amu}$ lower mass than hynapene $\mathrm{A}$ [7]. In contrast to the latter compound, both tanzawaic acids contain a double bond at C-14/15 instead of an $\mathrm{OH}$ group at C-14.

Biological activity. The isolated compounds were tested for their bioactivity in a series of antimicrobial and antiproliferative assays. We found that apart from compounds $\mathbf{1}$ and $\mathbf{2}$, the other isolates $(\mathbf{3}-\mathbf{8})$ inhibited the conidial germination in 
Magnaporthe oryzae at concentrations of $50 \mu \mathrm{g} / \mathrm{mL}$ or less (Table 3) whereas the germination of the grey mold Botrytis cinerea and the potato blight caused by the oomycete Phytophthora infestans were not affected at comparable concentrations. Even though several biological activities have been found for the known compounds 5-8, an inhibition of fungal spore germination of Magnaporthe oryzae was not reported to date. The structurally related hynapenes B and C showed antimicrobial activity against Pyricularia oryzae [8] whereas arohynapenes $\mathrm{A}, \mathrm{B}$, and $\mathrm{D}[3,9]$ were not active in agar diffusion assays. However, arohynapenes $\mathrm{A}$ and $\mathrm{B}$ inhibited the spore germination at $25 \mu \mathrm{g} / \mathrm{mL}$ ( $\mathrm{IC}_{90}$ ). In addition, tanzawaic acid A (7) showed weak activity in agar diffusion assays at $50 \mu \mathrm{g} /$ filter dics against Bacillus brevis, Mucor miehei, and Paecilomyces variotii, as well as cytotoxic effects against HeLaS3 cells at a concentration of $50 \mu \mathrm{g} / \mathrm{mL}$. However, none of the other compounds showed bioactivity in these assays up to $50 \mu \mathrm{g} / \mathrm{mL}$.

\begin{tabular}{|c|c|}
\hline Compound & M. oryzae $\mathrm{IC}_{90}[\mu \mathrm{g} / \mathrm{mL}]$ \\
\hline tanzawaic acid I (1) & - \\
\hline tanzawaic acid J (2) & - \\
\hline tanzawaic acid K (3) & 25 \\
\hline tanzawaic acid L (4) & 50 \\
\hline arohynapene A (5) & 25 \\
\hline arohynapene B (6) & 25 \\
\hline tanzawaic acid $\mathrm{A}(7)$ & 10 \\
\hline tanzawaic acid E (8) & 25 \\
\hline
\end{tabular}

\section{Experimental}

General experimental procedures. Optical rotations were measured on a Perkin Elmer polarimeter model 241 at 546 and $578 \mathrm{~nm}$ and were extrapolated to $589 \mathrm{~nm}$ using Drude's equation [10]. ${ }^{1} \mathrm{H},{ }^{13} \mathrm{C}$ and $2 \mathrm{D}$ NMR spectra were recorded on a Bruker AVANCE III $600 \mathrm{MHz}$ spectrometer equipped with a $5 \mathrm{~mm}$ TCI cryogenic inverse probe head (z-gradient) using standard pulse sequences. APCI-MS spectra were measured from a solution of the analyte in $\mathrm{MeCN} / \mathrm{H}_{2} \mathrm{O}$ with a Hewlett Packard MSD 1100 using an evaporator temperature of $400{ }^{\circ} \mathrm{C}$ and a drying gas temperature of $350{ }^{\circ} \mathrm{C}$ at a flow of $6 \mathrm{~L} / \mathrm{h}\left(\mathrm{N}_{2}\right)$. In positive ionization mode, the capillary voltage amounted to $3.5 \mathrm{kV}$, the corona discharge current was $4 \mu \mathrm{A}$. In negative ionization mode, the capillary voltage amounted to $2.2 \mathrm{kV}$, the corona discharge current was $6 \mu \mathrm{A}$. HRMS-ESI data were recorded on a Q-ToF ULTIMA-III (Waters) equipped with a LockSpray-interface. A Bruker IFS48 FTIR spectrometer and a Perkin-Elmer Lambda-16 spectrophotometer were used to measure the IR and UV spectra, respectively.
Producing organism. The producing fungus IBWF104-06 was isolated from a soil sample. The strain was determined as a Penicillium species by morphology. Strain IBWF104-06 has been deposited in the culture collection of the Institute of Biotechnology and Drug Research (IBWF e.V.), Kaiserslautern, Germany. For maintenance, the fungus was grown on agar slants on YMG agar (yeast extract $4.0 \mathrm{~g} / \mathrm{L}$, malt extract $10 \mathrm{~g} / \mathrm{L}$, glucose $10 \mathrm{~g} / \mathrm{L}$, the $\mathrm{pH}$ value was adjusted to 5.5 before sterilisation). Solid media contained $2.0 \%$ agar.

Fermentation and isolation. The fermentation was carried out according to the method described by Schüffler et al. [11]. The fungus was grown in YMG medium in a $20 \mathrm{~L}$ fermenter (Braun, Melsungen) at $22-24{ }^{\circ} \mathrm{C}$ with agitation (120 rpm) and aeration ( $3 \mathrm{~L} / \mathrm{min}$ ). For inoculation, a well-grown shake culture (YMG medium, $250 \mathrm{~mL}$ ) was used. During fermentation, the bioactive principles were quantified by HPLC and 13 days after inoculation the production was pronounced and the fermentation was stopped. The culture fluid $(14.5 \mathrm{~L})$ was separated from the mycelium by filtration and extracted with ethyl acetate $(10 \mathrm{~L})$. The solvent was evaporated and the oily crude extract (2.2 g) was applied onto a column filled with silica gel (Merck 60, $0.063-0.2 \mathrm{~mm}$ ). Elution with a mixture of cyclohexane/ethyl acetate $(3: 2 \mathrm{v} / \mathrm{v})$ yielded the oily fraction $1(700 \mathrm{mg}), 2: 3$ cyclohexane/ethyl acetate eluted oily fraction $2(560 \mathrm{mg})$, and 1:4 cyclohexane/ethyl acetate eluted oily fraction 3 (100 mg). Further work-up of fraction 1 by solid-phase extraction (Macherey-Nagel, Chromabond $\mathrm{C} 18 \mathrm{ec}$ ) with 1:1 acetonitrile/ water generated intermediate $\mathrm{A}(600 \mathrm{mg})$ and with 1:4 acetonitrile/water intermediate B $(50 \mathrm{mg})$. Preparative HPLC of intermediate A (Waters SunFire, Prep C18 OBD, $5 \mu \mathrm{m}$, $19 \times 250 \mathrm{~mm}, 17 \mathrm{~mL} / \mathrm{min}$, isocratic conditions, $1: 1$ acetonitrile/ $0.1 \%$ formic acid) resulted in arohynapene A $\left(5,173 \mathrm{mg}, t_{\mathrm{R}}\right.$ $9 \mathrm{~min})$ and tanzawaic acid E $\left(\mathbf{8}, 143 \mathrm{mg}, t_{\mathrm{R}} 13 \mathrm{~min}\right)$. Preparative HPLC of intermediate B resulted in tanzawaic acid A (7, $20 \mathrm{mg}, t_{\mathrm{R}} 24 \mathrm{~min}$; Waters SunFire, Prep C18 OBD, $5 \mu \mathrm{m}$, $19 \times 250 \mathrm{~mm}, 17 \mathrm{~mL} / \mathrm{min}$, isocratic conditions, 13:7 acetonitrile $/ 0.1 \%$ formic acid). Work-up of fraction 2 by preparative HPLC (Waters SunFire, Prep C18 OBD, $5 \mu \mathrm{m}, 19 \times 250 \mathrm{~mm}$, $17 \mathrm{~mL} / \mathrm{min}$, isocratic conditions, $11: 9$ acetonitrile $/ 0.1 \%$ formic acid) generated tanzawaic acid $\mathrm{K}\left(3,54 \mathrm{mg}, t_{\mathrm{R}} 16.5 \mathrm{~min}\right)$ and intermediate $\mathrm{C}\left(t_{\mathrm{R}} 7-13 \mathrm{~min}, 320 \mathrm{mg}\right)$. Intermediate $\mathrm{C}$ yielded tanzawaic acid L (4, $\left.29 \mathrm{mg}, t_{\mathrm{R}} 25.5 \mathrm{~min}\right)$ and arohynapene B (6, $14 \mathrm{mg}, t_{\mathrm{R}} 31 \mathrm{~min}$ ) by a second preparative HPLC (Agilent PrepHT, Zorbax, XDB-C8, $21.2 \times 150 \mathrm{~mm}, 5 \mu \mathrm{m}, 21 \mathrm{~mL} / \mathrm{min}$, isocratic conditions, 7:13 acetonitrile/0.1\% formic acid). Fraction 3 was applied onto a solid-phase extraction column (Macherey-Nagel, Chromabond $\mathrm{C} 18 \mathrm{ec}$ ) and extraction with 2:3 acetonitrile $/ 0.1 \%$ formic acid gave intermediate D $(87 \mathrm{mg})$ which was used for preparative HPLC (Waters SunFire, Prep $\mathrm{C} 18 \mathrm{OBD}, 5 \mu \mathrm{m}, 19 \times 250 \mathrm{~mm}, 16 \mathrm{~mL} / \mathrm{min}$, isocratic condi- 
tions, $2: 3$ acetonitrile $/ 0.1 \%$ formic acid) to yield tanzawaic acid $\mathrm{I}\left(\mathbf{1}, 7.7 \mathrm{mg}, t_{\mathrm{R}} 9 \mathrm{~min}\right)$ and tanzawaic acid $\mathrm{J}(2,12.6 \mathrm{mg}$, $\left.t_{\mathrm{R}} 10.5 \mathrm{~min}\right)$.

Bioactivity assays. Antimicrobial activities against bacteria and fungi were determined in the agar plate diffusion assay as described previously [12]. Cytotoxicity was assayed as described previously [13]. The cell line HelaS3 was grown in DMEM medium (Invitrogen). The medium was supplemented with $10 \%$ heat-inactivated fetal calf serum (Invitrogen), $65 \mathrm{mg} / \mathrm{L}$ of penicillin $\mathrm{G}$ and $100 \mathrm{mg} / \mathrm{L}$ of streptomycin sulfate. The viability was evaluated by microscopy after $72 \mathrm{~h}$. The spore germination was tested with $M$. oryzae as described previously [14]. This method was adapted for the spore germination assay with Phytophthora infestans and Botrytis cinerea.

Tanzawaic acid I (1). Yellow oil; UV $(\mathrm{MeOH})\left(\lambda_{\max }, \log \varepsilon\right)$ : 261 (4.45); $[\alpha]_{\mathrm{D}}{ }^{20}-262(0.4, \mathrm{MeOH}) ; \mathrm{IR}\left(v, \mathrm{~cm}^{-1}\right): 3414,2950$, 2923, 1689, 1640, 1457, 1380, 1248; HRMS-ESI $m / z$ : [M + $\mathrm{Na}]^{+}$calcd for $\mathrm{C}_{18} \mathrm{H}_{26} \mathrm{O}_{4} \mathrm{Na}$, 329.1729; found, 329.1744; APCIMS (neg) $m / z$ : $305.1[\mathrm{M}-\mathrm{H}]^{-}$; APCI-MS (pos) $m / z$ : $289.2[\mathrm{M}$ $\left.-\mathrm{H}_{2} \mathrm{O}+\mathrm{H}\right]^{+}, 271.2\left[\mathrm{M}-2 \mathrm{H}_{2} \mathrm{O}+\mathrm{H}\right]^{+}$.

Tanzawaic acid $\mathbf{J}$ (2). Yellow oil; UV $(\mathrm{MeOH})\left(\lambda_{\max }, \log \varepsilon\right)$ : 261 (4.45); $[\alpha]_{\mathrm{D}}{ }^{20}+73.7(0.4, \mathrm{MeOH}) ; \mathrm{IR}\left(v, \mathrm{~cm}^{-1}\right): 3369$, 2947, 2835, 1638, 1451, 1032; HRMS-ESI $m / z:[\mathrm{M}+\mathrm{Na}]^{+}$ calcd for $\mathrm{C}_{18} \mathrm{H}_{26} \mathrm{O}_{4} \mathrm{Na}$, 329.1729; found, 329.1744; APCI-MS (neg) $m / z: 305.1[\mathrm{M}-\mathrm{H}]^{-}$; APCI-MS (pos) $m / z$ : $289.2[\mathrm{M}-$ $\left.\mathrm{H}_{2} \mathrm{O}+\mathrm{H}\right]^{+}, 271.2\left[\mathrm{M}-2 \mathrm{H}_{2} \mathrm{O}+\mathrm{H}\right]^{+}$.

Tanzawaic acid K (3). Yellow oil; UV (MeOH) $\left(\lambda_{\max }, \log \varepsilon\right)$ : 257 (4.59); $[\alpha]_{\mathrm{D}}{ }^{20}-20.1(0.38, \mathrm{MeOH}) ; \mathrm{IR}\left(v, \mathrm{~cm}^{-1}\right): 3432$, 2909, 1688, 1638, 1456, 1275; HRMS-ESI $m / z:[\mathrm{M}+\mathrm{Na}]^{+}$ calcd for $\mathrm{C}_{18} \mathrm{H}_{26} \mathrm{O}_{3} \mathrm{Na}$, 313.1780; found, 313.1788; APCI-MS (neg) $m / z: 289.1[\mathrm{M}-\mathrm{H}]^{-}$; APCI-MS (pos) $m / z: 273.2[\mathrm{M}-$ $\left.\mathrm{H}_{2} \mathrm{O}+\mathrm{H}\right]^{+}$.

Tanzawaic acid L (4). Yellow oil; UV $(\mathrm{MeOH})\left(\lambda_{\max }, \log \varepsilon\right)$ : 255 (3.70), 286 (3.68); $[\alpha]_{\mathrm{D}}{ }^{20}-126.7(0.32, \mathrm{MeOH})$; IR $\left(v, \mathrm{~cm}^{-1}\right): 3409,2961,2965,1698,1638,1377,1247$; HRMS-ESI $m / z$ : $[\mathrm{M}+\mathrm{Na}]^{+}$calcd for $\mathrm{C}_{18} \mathrm{H}_{24} \mathrm{O}_{3} \mathrm{Na}, 311.1623$; found, 311.1630; APCI-MS (neg) $m / z: 287.1[\mathrm{M}-\mathrm{H}]^{-}$; APCI-MS (pos) $m / z: 271.1\left[\mathrm{M}-\mathrm{H}_{2} \mathrm{O}+\mathrm{H}\right]^{+}, 253.1\left[\mathrm{M}-2 \mathrm{H}_{2} \mathrm{O}\right.$ $+\mathrm{H}]^{+}$.

CCDC 962065 and 962066 contain crystallographic data for arohynapene A and tanzawaic acid E, respectively. A copy of the data can be obtained free of charge from the Cambridge Crystallographic Data Centre, on application to CCDC, 12 Union Road, Cambridge CB2 1EZ, UK, (fax: +44-(0)1223336033 or e-mail:deposit@ccdc.cam.ac.uk).

\section{Supporting Information}

\section{Supporting Information File 1}

NMR spectra and crystallographic data.

[http://www.beilstein-journals.org/bjoc/content/

supplementary/1860-5397-10-20-S1.pdf]

\section{Acknowledgements}

We thank the Rhineland Palatinate Center for Natural Product Research for financial support, Prof. Dr. H. Anke (IBWF, Kaiserslautern) for providing the strain IBWF104-06, Nina Wolff and Anja Meffert (both Kaiserslautern) for expert technical assistance, Dr. Johannes C. Liermann (Mainz) for NMR spectroscopy, Dr. N. Hanold (Mainz) for mass spectrometry, and Dr. D. Schollmeyer (Mainz) for X-ray crystallography.

\section{References}

1. Kuramoto, M.; Yamada, K.; Shikano, M.; Yazawa, K.; Arimoto, H.; Okamura, T.; Uemura, D. Chem. Lett. 1997, 26, 885-886. doi:10.1246/cl.1997.885

2. Malmstrøm, J.; Christophersen, C.; Frisvad, J. C. Phytochemistry 2000, 54, 301-309. doi:10.1016/S0031-9422(00)00106-0

3. Masuma, R.; Tabata, N.; Tomoda, H.; Haneda, K.; Iwai, Y.; Omura, S. J. Antibiot. 1994, 47, 46-53. doi:10.7164/antibiotics.47.46

4. Arimoto, H.; Nishimura, K.; Kuramoto, M.; Uemura, D. Tetrahedron Lett. 1998, 39, 9513-9516. doi:10.1016/S0040-4039(98)02226-6

5. El-Neketi, M.; Ebrahim, W.; Lin, W.; Gedara, S.; Badria, F.; Saad, H.-E. A.; Lai, D.; Proksch, P. J. Nat. Prod. 2013, 76, 1099-1104. doi:10.1021/np4001366

6. Houbraken, J.; Frisvad, J. C.; Samson, R. A. Stud. Mycol. 2011, 70, 53-138. doi:10.3114/sim.2011.70.02

7. Tabata, N.; Tomoda, H.; Iwai, Y.; Omura, S. J. Antibiot. 1993, 46, 1854-1858. doi:10.7164/antibiotics.46.1854

8. Tabata, N.; Tomoda, H.; Masuma, R.; Haneda, K.; Iwai, Y.; Omura, S. J. Antibiot. 1993, 46, 1849-1853. doi:10.7164/antibiotics.46.1849

9. Tabata, N.; Tomoda, H.; Iwai, Y.; Omura, S. J. Antibiot. 1995, 48, 83-84. doi:10.7164/antibiotics.48.83

10. Lippke, G.; Thaler, H. Starch/Staerke 1970, 22, 344-351. doi:10.1002/star.19700221005

11. Schüffler, A.; Kautz, D.; Liermann, J. C.; Opatz, T.; Anke, T. J. Antibiot. 2009, 62, 119-121. doi:10.1038/ja.2008.21

12. Anke, H.; Bergendorff, O.; Sterner, O. Food Chem. Toxicol. 1989, 27, 393-397. doi:10.1016/0278-6915(89)90145-2

13. Zapf, S.; Hoßfeld, M.; Anke, H.; Velten, R.; Steglich, W. J. Antibiot. 1995, 48, 36-41. doi:10.7164/antibiotics.48.36

14. Kettering, M.; Valdivia, C.; Sterner, O.; Anke, H.; Thines, E. J. Antibiot. 2005, 58, 390-396. doi:10.1038/ja.2005.49 


\section{License and Terms}

This is an Open Access article under the terms of the Creative Commons Attribution License

(http://creativecommons.org/licenses/by/2.0), which permits unrestricted use, distribution, and reproduction in any medium, provided the original work is properly cited.

The license is subject to the Beilstein Journal of Organic Chemistry terms and conditions:

(http://www.beilstein-journals.org/bjoc)

The definitive version of this article is the electronic one which can be found at:

doi:10.3762/bjoc. 10.20 